\title{
Stability Analysis of Grid-Connected Inverters with an LCL Filter Considering Grid Impedance
}

\author{
Xiao-Qiang $\mathrm{Li}^{*}$, Xiao-Jie $\mathrm{Wu}^{\dagger}$, Yi-Wen Geng ${ }^{*}$, and Qi Zhang ${ }^{*}$ \\ $\dagger^{* *}$ Dept. of Information and Electrical Eng., China University of Mining and Technology, Xuzhou, China
}

\begin{abstract}
Under high grid impedance conditions, it is difficult to guarantee the stability of grid-connected inverters with an LCL filter designed based on ideal grid conditions. In this paper, the theoretical basis for output impedance calculation is introduced. Based on the small-signal model, the $d$ - $d$ channel closed-loop output impedance models adopting the converter-side current control method and the grid-side current control method are derived, respectively. Specifically, this paper shows how to simplify the stability analysis which is usually complemented based on the generalized Nyquist stability criterion (GNC). The stability of each current-controlled grid-connected system is analyzed via the proposed simplified method. Moreover, the influence of the LCL parameters on the stability margin of grid-connected inverter controlled with converter-side current is studied. It is shown that the stability of grid-connected systems is fully determined by the $d-d$ channel output admittance of the grid-connected inverter and the inductive component of the grid impedance. Experimental results validate the proposed theoretical stability analysis.
\end{abstract}

Key words: $d-d$ channel output impedance, Grid impedance, Grid-connected inverter, LCL filter, Stability

\section{INTRODUCTION}

In recent years, distributed generation (DG) systems based on renewable energy have been increasingly focused due to the characteristics of design flexibility, high reliability and convenient maintenance. Since grid-connected inverters are the key ingredient for new energy power generation technology, it is vital to analyze their stability.

Compared with L filters, LCL filters have better suppression performance on high frequency harmonics. On the condition that the total inductance of the LCL filter is far less than that of the L filter, the LCL filter can have the same filtering performance, especially when adapted in low switch frequency applications. Grid-connected inverters with an LCL filter have been widely accepted in applications for wind power generation, photovoltaic power generation, etc.

Generally, the designing of a grid-connected inverter does not consider the influence of grid impedance [1]. Basically, a

Manuscript received Mar. 7, 2013; revised Jul. 20, 2013

Recommended for publication by Associate Editor Kyo-Beum Lee.

†Corresponding Author: zgcumt@126.com

Tel: +86-15852171104, Fax: +86-0516-83885667, China Univ. of

Mining and Tech.

*Dept. of Information and Electrical Eng., China University of Mining and Technology, China number of grid-connected inverters are installed in remote areas and the grid impedance at the point of common coupling (PCC) is relatively high due to long distribution wires and low power transformers [2]. Thus the negative influences on the performances and stability of the inverters should not be neglected [3]. A very limited amount of literature on the use of grid connected inverters in high grid impedance conditions is available. The influence of grid impedance on the stability of grid-connected inverters has been analyzed from the perspective of the resonance of LCL filters [2]. However, this approach has its limitation since it cannot solve the stability problems of grid-connected inverters cascaded with the grid from a macroscopic point of view.

Based on the Middlebrook impedance criterion and other improved impedance criteria [4], [5], the corresponding relationships between the stability and the output/input impedance of cascaded systems have been established [6]-[8]. However, the Middlebrook impedance criterion is mainly applicable to DC distributed power supply systems, whereas it cannot be adapted directly into three-phase grid-connected inverters. Sun [9] has analyzed the stability problems of cascaded systems between grid-connected inverters and a high impedance grid. This study lacked an effective 
impedance criterion and the stability region was not determined for cascaded systems. On the basis of Middlebrook's work, Hiti et al [10] proposed a study of the $d-q$ frame return-ratio matrix to study the stability of threephase ac power systems, using the conventional multivariable linear control theory to limit the impedance magnitudes. Belkhayat [11] first studied the stability of ac interfaces in the $d-q$ frame by employing the GNC, in 1997. This criterion was developed by Macfarlane and Postlethwaite in the 1970's [12]. To simplify the stability analysis, the authors of [13] proposed $d-d$ channel stability criterion based on the GNC to study the interactions between a three-phase PWM boost rectifier and its EMI filter.

In order to determine the stability of a system according to the impedance criterion, the impedance of the converter needs to be modeled [14]. In [15], the input impedance of a single-phase PWM rectifier with an LCL filter was modeled. Since LCL filters are characterized by their high order, strong coupling and nonlinearity, the input/output impedance of the converter cannot be expressed exactly by adopting the largesignal impedance analysis method. By means of the smallsignal disturbance linearization near a certain operating point in the averaged linearized model, the small-signal impedance model is obtained [16]-[20], and then the stability of the system can be determined and analyzed accurately via the impedance criterion. The frequency characteristic of the converter's input/output impedances is measured by injecting small signals [21], [22]. The system stability can be determined by the measured impedance ratio curves, but additional hardware equipment is required.

This paper analyzes the stability of grid-connected inverters with an LCL filter while considering the grid impedance. In Section II, the theoretical basis for the output impedance calculation is introduced and a small-signal model of the grid-connected converter is constructed. Then the $d-d$ channel output impedance models controlled with the converter-side current and the grid-side current are derived, respectively. In Section III, taking the grid impedance into account, the stability analysis which adopts the GNC to study the return-ratio matrix is simplified. The stability of each current-controlled grid-connected system is analyzed via the proposed simplified method. In addition, the influence of the LCL parameters on the stability margin of grid-connected inverters controlled with the converter-side current is studied. In order to validate the theoretical analysis on stability, a $10 \mathrm{~kW}$ experimental prototype is built and tested. Experimental waveforms are presented in Section IV. Finally, Section V concludes this paper.

\section{II. $D$ - $D$ Channel Closed-Loop OUtPut IMPEDANCE MODEL}

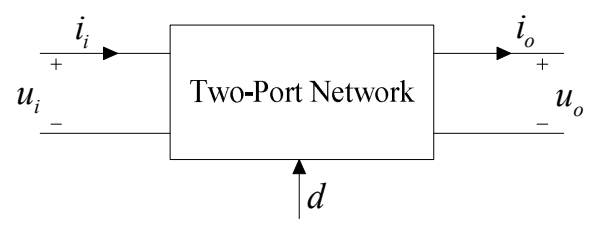

Fig. 1. Two-port network.

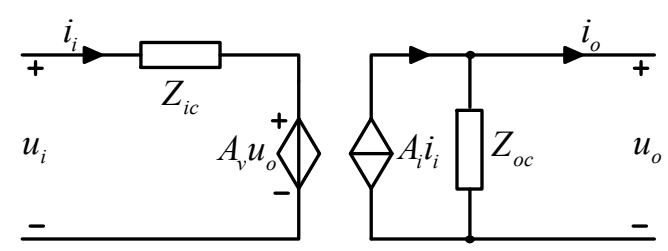

Fig. 2. Equivalent circuit of two-port network.

\section{A. Theoretical Basis for Output Impedance Calculation}

Fig. 1 shows a two-port network, where $u_{i}$ and $u_{o}$ denote the input and output port voltage, $i_{i}$ and $i_{o}$ denote the input and output current, and $d$ denotes the duty cycle. The basic relationship of the variables is shown as follows:

$$
\left\{\begin{array}{l}
i_{o}=-\frac{1}{Z_{o o}} u_{o}+G_{i d} d+A_{i i} i_{i} \\
u_{i}=Z_{i o} i_{i}+G_{v d} d+A_{v v} u_{o}
\end{array}\right.
$$

where $Z_{o o}$ denotes the open-loop output impedance, $G_{i d}$ denotes the transfer function from the duty cycle $d$ to the output current, $A_{i i}$ denotes the open-loop transfer function from the input current to the output current, $Z_{i o}$ denotes the open-loop input impedance, $G_{v d}$ denotes the transfer function from the duty cycle $d$ to the output voltage, and $A_{v v}$ denotes the transfer function from the output voltage to the input voltage [5], [18].

According to the Thevenin theorem and the Norton theorem, the equivalent circuit of a two-port network is presented in Fig. 2. $Z_{o c}$ denotes the closed-loop output impedance, $A_{i}$ denotes the closed-loop transfer function from the input current to the output current, $Z_{i c}$ denotes the closed-loop input impedance, and $A_{v}$ denotes the closedloop transfer function from the output voltage to the input voltage.

This paper only considers the closed-loop output impedance [19], [23]. The equation is shown as (2).

$$
Z_{o c}=-\left.\frac{u_{o}}{i_{o}}\right|_{i_{i}=0}
$$

\section{B. D-D Channel Output Impedance of Three-Phase Grid-Connected Inverter}




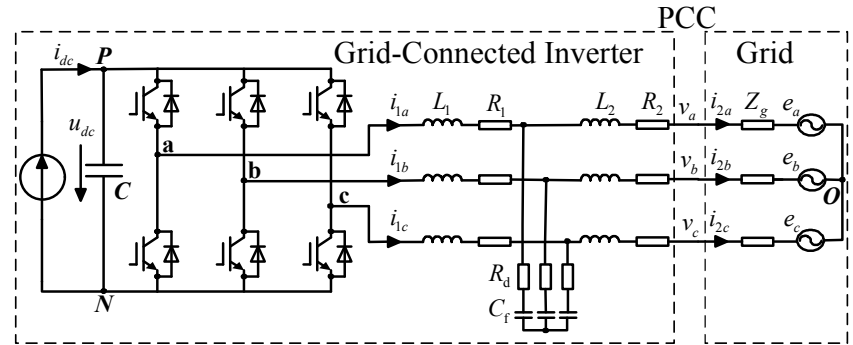

Fig. 3. Topology of grid-connected inverter with LCL filter.

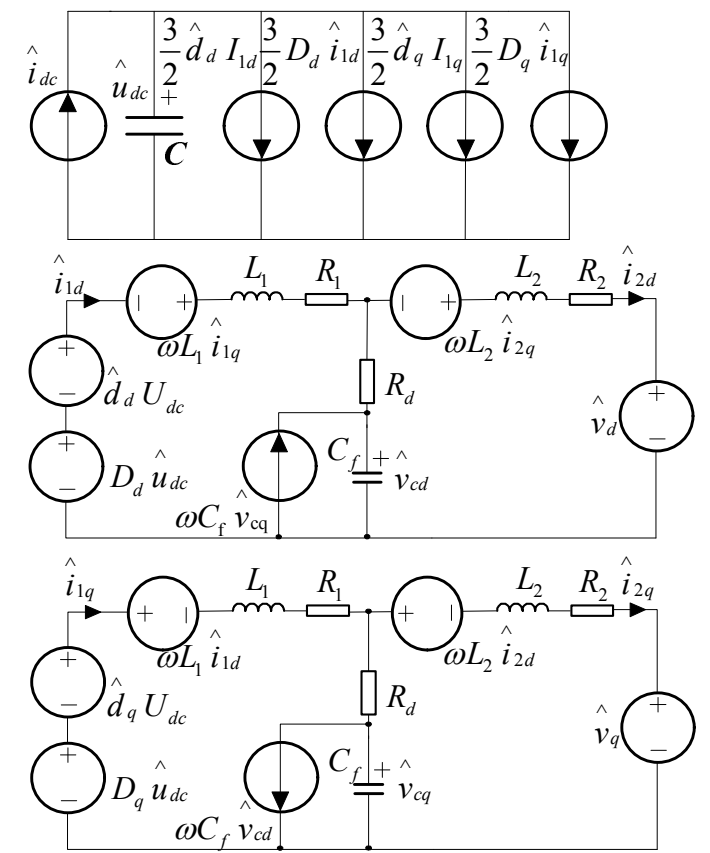

Fig. 4. Small-signal circuit in the SRF of grid-connected inverter with LCL filter.

Fig. 3 shows the topology of a grid-connected inverter with an LCL filter. $L_{1}$ and $L_{2}$ denote the inductances on the converter side and the grid side, respectively. $R_{1}$ and $R_{2}$ are the equivalent resistances of the filter inductances. $R_{d}$ denotes the damping resistance of the LCL filter, $C_{f}$ denotes the filter capacitance, $Z_{g}$ denotes the grid impedance, $e_{k}(k=a, b, c)$ denotes the ideal grid voltage, and $v_{k}(k=a, b, c)$ denotes the voltage of the PCC.

Fig. 4 shows the small-signal circuit in the synchronous rotating frame (SRF) of a grid-connected inverter with an LCL filter [24], [25]. In Fig. 4, $\omega L_{1} \hat{i}_{1 q}, \omega L_{2} \hat{i}_{2 q}, \omega L_{1} \hat{i}_{1 d}$ and $\omega L_{2} \hat{i}_{2 d}$ are the coupling terms of the current in the inductors. $\omega C_{f} \hat{v}_{c q}$ and $\omega C_{f} \hat{v}_{c d}$ are the coupling terms of the voltage in the capacitors. $U_{d c}, D_{d}, D_{q}, I_{1 d}$ and $I_{1 q}$ are the constants at the stable operating point of the grid-connected inverter. $\hat{i}_{1 d}$ and $\hat{i}_{1 q}$ are the converter-side current. $\hat{i}_{2 d}$ and

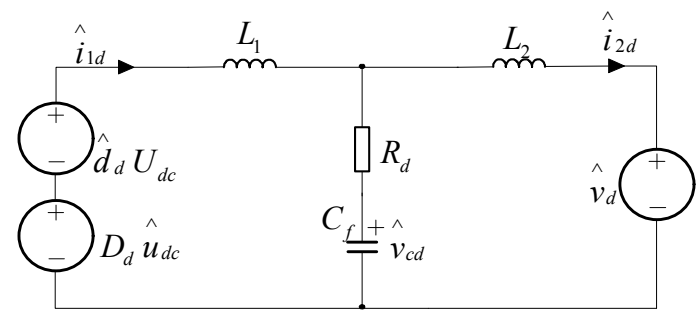

Fig. 5. $D$ channel small-signal circuit.

$\hat{i}_{2 q}$ are the grid-side current. $\hat{d}_{d}$ and $\hat{d}_{q}$ are the duty cycle. $\hat{i}_{d c}$ and $\hat{u}_{d c}$ are the DC-side current and voltage, respectively.

The small-signal circuit model in Fig.4 is multivariable and strongly coupled. Due to the coupling terms, the output impedance can be described as a second order matrix.

$$
\mathbf{Z}_{o c}=\left[\begin{array}{ll}
Z_{d d} & Z_{d q} \\
Z_{q d} & Z_{q q}
\end{array}\right]
$$

where $Z_{d d}$ and $Z_{q q}$ are the $d-d$ channel and $q-q$ channel impedances, respectively. $Z_{d q}$ and $Z_{q d}$ are the cross-coupled impedances [13], [26].

To obtain the $d$ - $d$ channel output impedance of the gridconnected inverter, the coupling terms in Fig. 4 are neglected. Then the $d$ channel small-signal circuit is shown as Fig. 5. $R_{1}$ and $R_{2}$ are neglected because of their small values.

According to the small-signal circuit in Fig. 5, the transfer function from the duty cycle $d$ to the converter-side current $i_{1 d}$ is described as follows:

$G_{i d 1}(s)=\frac{U_{d c}\left(s^{2} C_{f} L_{2}+s C_{f} R_{d}+1\right)}{s^{3} C_{f} L_{1} L_{2}+s^{2} C_{f} R_{d}\left(L_{1}+L_{2}\right)+s\left(L_{1}+L_{2}\right)}$

The transfer function from the duty cycle $d$ to the gridside current $i_{2 d}$ is described as follows:

$G_{i d 2}(s)=\frac{U_{d c}\left(s C_{f} R_{d}+1\right)}{s^{3} C_{f} L_{1} L_{2}+s^{2} C_{f} R_{d}\left(L_{1}+L_{2}\right)+s\left(L_{1}+L_{2}\right)}$

The transfer function from the grid voltage $v_{d}$ to the converter-side current $i_{1 d}$ is described as follows:

$G_{i v}(s)=-\frac{s C_{f} R_{d}+1}{s^{3} C_{f} L_{1} L_{2}+s^{2} C_{f} R_{d}\left(L_{1}+L_{2}\right)+s\left(L_{1}+L_{2}\right)}$

The $d$ - $d$ channel open-loop output impedance is described as follows:

$Z_{\text {oo }}(s)=\frac{s^{3} C_{f} L_{1} L_{2}+s^{2} C_{f} R_{d}\left(L_{1}+L_{2}\right)+s\left(L_{1}+L_{2}\right)}{s^{2} C_{f} L_{1}+s C_{f} R_{d}+1}$ 


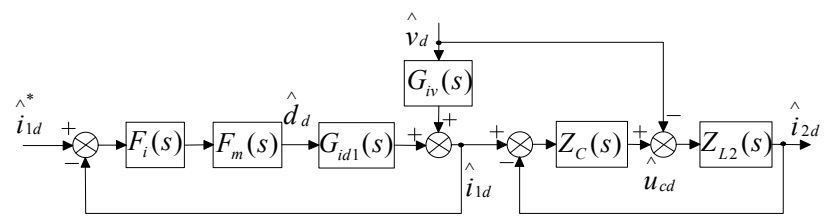

(a) Controlled with converter-side current.

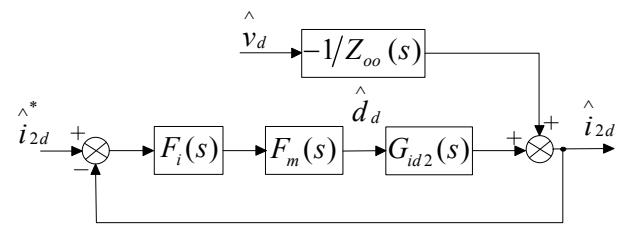

(b) Controlled with grid-side current.

Fig. 6. Block diagrams of current control structures of gridconnected inverter with LCL filter via each current control method.

The detailed expressions of (4)-(7) are shown in the Appendix. According to (1) and (2), the block diagrams of the current control structures of a grid-connected inverter with an LCL filter controlled with the converter-side current and the grid-side current are shown in Fig. 6, where $F_{i}(s)$ is the transfer function of the current regulator described as follows:

$$
F_{i}(s)=k_{p}+\frac{k_{i}}{s}
$$

$F_{m}(s)$ is the first order inertial element of the converter [27]. $K_{P W M}$ denotes the bridge circuit gain.

$$
F_{m}(s)=\frac{K_{P W M}}{1.5 T_{s} s+1}
$$

The $d$ - $d$ channel closed-loop output impedance of the grid-connected inverter with the converter current control is shown as follows:

$$
Z_{d d 1}(s)=-\frac{\hat{v}_{d}}{\hat{i}_{2 d}}=\frac{s^{2} C_{f} L_{2}+s C_{f} R_{d}+1}{\frac{\left(s C_{f} R_{d}+1\right)^{2}}{\Delta(s)\left(1+T_{m 1}(s)\right)}+s C_{f}}
$$

where $\Delta(s)=s^{3} C_{f} L_{1} L_{2}+s^{2} C_{f} R_{d}\left(L_{1}+L_{2}\right)+s\left(L_{1}+L_{2}\right)$, and $T_{m 1}(s)=F_{i}(s) F_{m}(s) G_{i d 1}(s)$ is the loop gain controlled with the converter-side current control.

The $d$ - $d$ channel closed-loop output impedance of the gridconnected inverter with the grid current control is shown as follows:

$$
Z_{d d 2}(s)=-\frac{\hat{v}_{d}}{\hat{i}_{2 d}}=Z_{o o}(s)\left(1+T_{m 2}(s)\right)
$$

where $T_{m 2}(s)=F_{i}(s) F_{m}(s) G_{i d 2}(s)$ denotes the loop gain controlled with the grid-side current.

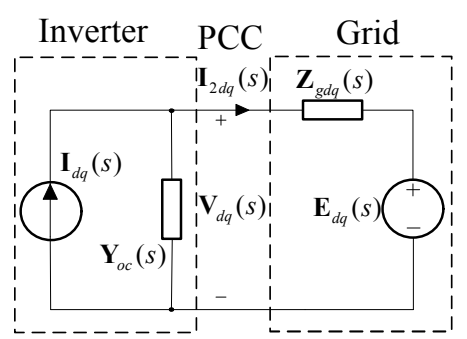

Fig. 7. Equivalent circuit in the SRF for the cascaded system of the grid-connected inverter and the grid.

The expanded expressions of $Z_{d d 1}(s)$ and $Z_{d d 2}(s)$ are rather complicated and shown in the Appendix.

\section{STABILITY ANALYSIS OF THE GRID-CONNECTED INVERTER}

\section{A. Simplified Stability Criterion}

Based on the power circuit in Fig. 3 and the impedance models of the grid-connected inverter in section II, the equivalent circuit in the SRF for the cascaded system of the grid-connected inverter and the grid is shown in Fig. 7.

In Fig.7, $\mathbf{Z}_{g d q}(s)$ denotes the grid impedance matrix, $\mathbf{Y}_{o c}(s)$ denotes the output admittance matrix of the gridconnected inverter, $\mathbf{V}_{d q}(s)$ denotes the voltage matrix at the PCC, $\mathbf{E}_{d q}(s)$ denotes the grid voltage matrix, and $\mathbf{I}_{2 d q}(s)$ denotes the grid current matrix.

$$
\mathbf{V}_{d q}(s)=\left[\begin{array}{l}
v_{d} \\
v_{q}
\end{array}\right] \quad \mathbf{E}_{d q}(s)=\left[\begin{array}{l}
e_{d} \\
e_{q}
\end{array}\right] \quad \mathbf{I}_{2 d q}(s)=\left[\begin{array}{l}
i_{2 d} \\
i_{2 q}
\end{array}\right]
$$

Generally, the grid impedance is inductive. The grid impedance in Fig. 3 is defined as follows:

$$
Z_{g}=s L_{g}+R_{g}
$$

Then the grid impedance matrix is shown as:

$\mathbf{Z}_{g d q}(s)=\left[\begin{array}{cc}Z_{g d d}(s) & Z_{g d q}(s) \\ Z_{g q d}(s) & Z_{g q q}(s)\end{array}\right]=\left[\begin{array}{cc}s L_{g}+R_{g} & -\omega L_{g} \\ \omega L_{g} & s L_{g}+R_{g}\end{array}\right]$

The output admittance matrix of the grid-connected inverter is shown as:

$$
\mathbf{Y}_{o c}=\left[\begin{array}{ll}
Y_{d d} & Y_{d q} \\
Y_{q d} & Y_{q q}
\end{array}\right]
$$

$Y_{d q}$ and $Y_{q d}$ are far less than $Y_{d d}$ and $Y_{q q}$. Therefore, $Y_{d q}$ and $Y_{q d}$ can be neglected [13],[26] and (15) can be expressed as:

$$
\mathbf{Y}_{o c} \approx\left[\begin{array}{cc}
Y_{d d} & 0 \\
0 & Y_{q q}
\end{array}\right]=\left[\begin{array}{cc}
1 / Z_{d d} & 0 \\
0 & 1 / Z_{q q}
\end{array}\right]
$$

Due to the symmetrical characteristic of $d$ channel and $q$ channel, $Z_{d d}=Z_{q q}$. (16) can be written as: 


$$
\mathbf{Y}_{o c} \approx\left[\begin{array}{cc}
Y_{d d} & 0 \\
0 & Y_{d d}
\end{array}\right]=\left[\begin{array}{cc}
1 / Z_{d d} & 0 \\
0 & 1 / Z_{d d}
\end{array}\right]
$$

The output current of the grid-connected inverter in Fig. 7 is expressed as:

$$
\mathbf{I}_{2 d q}(s)=\left(\mathbf{I}+\mathbf{Z}_{g d q}(s) \mathbf{Y}_{o c}(s)\right)^{-1}\left(\mathbf{I}_{d q}(s)-\mathbf{Y}_{o c}(s) \mathbf{E}_{d q}(s)\right)(18)
$$

Under the condition of an ideal grid, the grid-connected inverter is assumed to work well and steadily. According to (18), when cascading the high-impedance grid, the system is stable if the return-ratio matrix $\mathbf{Z}_{g d q}(s) \mathbf{Y}_{o c}(s)$ satisfies the generalized Nyquist stability criterion and a sufficient stability margin is guaranteed.

The return-ratio matrix is written in expanded form in the following way:

$$
\begin{aligned}
\mathbf{L}_{d q}(s) & =\mathbf{Z}_{g d q}(s) \mathbf{Y}_{o c}(s) \\
& \approx\left[\begin{array}{cc}
Z_{g d d}(s) & Z_{g d q}(s) \\
Z_{g q d}(s) & Z_{g q q}(s)
\end{array}\right]\left[\begin{array}{cc}
Y_{d d}(s) & 0 \\
0 & Y_{d d}(s)
\end{array}\right]
\end{aligned}
$$

According to (14), the following equations are derived as:

$$
Z_{g d d}(s)=Z_{g q q}(s) \quad Z_{g d q}(s)=-Z_{g q d}(s)
$$

Substituting (20) into (19) yields:

$$
\mathbf{L}_{d q}(s) \approx\left[\begin{array}{cc}
Z_{g d d}(s) Y_{d d}(s) & Z_{g d q}(s) Y_{d d}(s) \\
-Z_{g d q}(s) Y_{d d}(s) & Z_{g d d}(s) Y_{d d}(s)
\end{array}\right]
$$

Since $\mathbf{L}_{d q}(s)$ is the second order matrix, it consist of two eigenvalues $l_{1}(s)$ and $l_{2}(s)$. According to the generalized Nyquist stability criterion [12], the grid-connected system is stable if and only if the net sum of the anticlockwise encirclements of the critical point $(-1, j 0)$ by the set of characteristic loci of $\mathbf{L}_{d q}(s)$ is equal to the total number of right-half plane poles for the grid-impedance matrix $\mathbf{Z}_{g d q}(s)$ and the output admittance matrix $\mathbf{Y}_{o c}(s)$ of the grid-connected inverter.

The eigenvalues of the return-ratio matrix $\mathbf{L}_{d q}(s)$ are derived as follows:

$$
\left\{\begin{array}{l}
l_{1}(s)=Z_{g d d}(s) Y_{d d}(s)+j Z_{g d q}(s) Y_{d d}(s) \\
l_{2}(s)=Z_{g d d}(s) Y_{d d}(s)-j Z_{g d q}(s) Y_{d d}(s)
\end{array}\right.
$$

Combining (14) and (22), the following equation is derived as:

$$
\left\{\begin{array}{l}
l_{1}(s)=\left(s L_{g}+R_{g}+j \omega L_{g}\right) Y_{d d}(s) \\
l_{2}(s)=\left(s L_{g}+R_{g}-j \omega L_{g}\right) Y_{d d}(s)
\end{array}\right.
$$

Table I shows the parameters of the grid-connected system studied in this paper. The inductance $L_{g}$ and the resistance $R_{g}$ in the grid impedance are assumed to be $1 \mathrm{mH}$ and $1 \Omega$, respectively. Thus the Nyquist plots for the eigenvalues of the
TABLE I

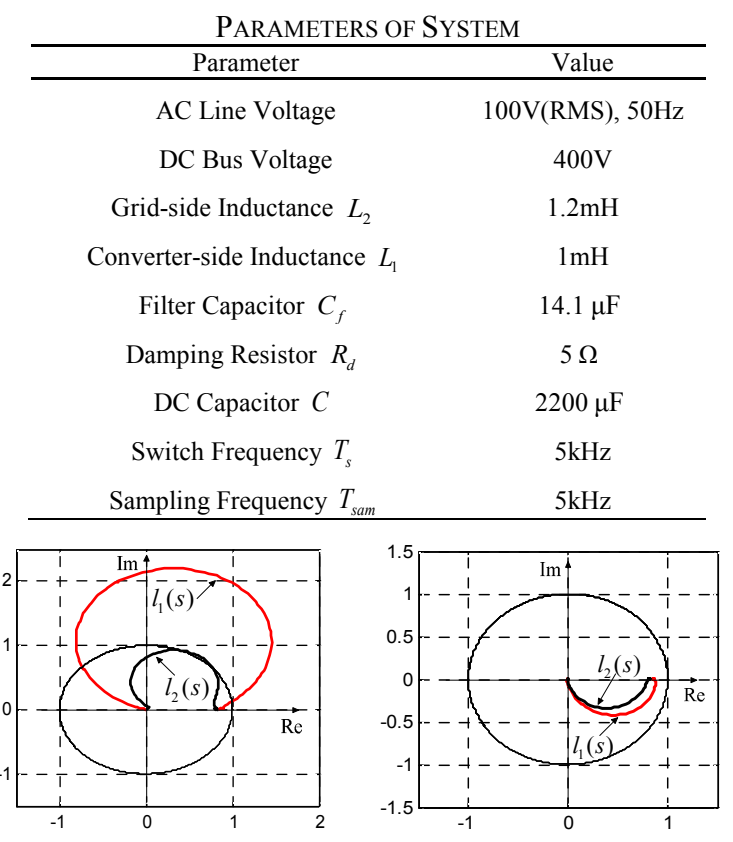

(a)

(b)

Fig. 8. Nyquist plots for the eigenvalues of the return-ratio matrix $\mathbf{L}_{d q}(s)$. (a) Controlled with converter-side current; (b) Controlled with grid-side current.

return-ratio matrix $\mathbf{L}_{d q}(s)$ are shown in Fig. 8 with the parameters listed in Table I.

In Fig. 8(a), the Nyquist diagram for $l_{2}(s)$ is almost in the unit circle and does not intersect with the unit circle on the left plane of the complex plane. Whereas $l_{1}(s)$ presents large magnitude and does not encircle about $(-1, j 0)$, it intersects with the unit circle on the left plane of the complex plane and it influences the stability margin of the system. In Fig. 8(b), the Nyquist diagrams for $l_{1}(s)$ and $l_{2}(s)$ reside completely on the right plane of the complex plane and are unable to encircle about $(-1, j 0)$ or intersect with the unit circle on the left plane of the complex plane.

\section{B. The Stability of Grid-Connected Inverters with Two Current Control Methods}

The grid impedance matrix $\mathbf{Z}_{g d q}(s)$ does not have righthalf plane poles. This paper concentrates on the poles of the output admittance matrix $\mathbf{Y}_{o c}(s)$ of the grid-connected inverter. Since $\mathbf{Y}_{o c}(s)$ in (17) is in the Smith-Mcmillan form, the poles of the admittance matrix $\mathbf{Y}_{o c}(s)$ are the poles of $Y_{d d}(s)$. Fig. 9 shows zero-pole plots for $Y_{d d}(s)$ via two control methods with the parameters listed in Table I. From Fig. 9, it can be observed that the output admittance matrix 


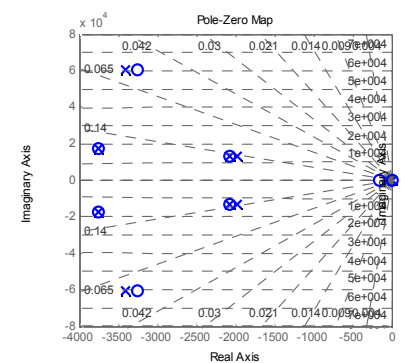

(a)

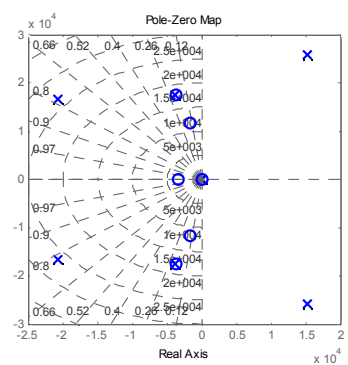

(b)
Fig. 9. The zero-pole plot for the $d$ - $d$ channel output admittance $Y_{d d}(s)$. (a) Controlled with converter-side current; (b)

Controlled with grid-side current.

$\mathbf{Y}_{o c}(s)$ of the grid-connected inverter has conjugate poles with a positive real part when the system is controlled with the grid-side current. Moreover, it can be observed from Fig. 8(b) that the Nyquist plots for the eigenvalues $l_{1}(s)$ and $l_{2}(s)$ of the return-ratio matrix $\mathbf{L}_{d q}(s)$ does not encircle the point $(-1, j 0)$. Therefore, the grid-connected system with an LCL filter controlled with the grid-side current does not satisfy the generalized Nyquist stability criterion and the system is unstable. By comparison, when the system is controlled with the converter-side current, the Nyquist plots for the eigenvalues $l_{1}(s)$ and $l_{2}(s)$ of the return-ratio matrix $\mathbf{L}_{d q}(s)$ does not encircle the point $(-1, j 0)$ and the output admittance matrix $\mathbf{Y}_{o c}(s)$ does not have poles with a positive real part. Thus the system satisfies the generalized Nyquist stability criterion.

\section{Stability Margin of a Grid-Connected Inverter Controlled with the Converter-side Current}

When the system is controlled with the grid-side current, the grid-connected system does not satisfy the generalized Nyquist stability criterion. This section mainly analyzes the stability margin of a grid-connected inverter controlled with the converter-side current.

As for closed-loop control system, a certain stability margin should be required in addition to satisfying the generalized Nyquist stability criterion. Generally, in order to guarantee sufficient stability of the grid-connected system, that phase margin $P M>60^{\circ}$ and magnitude margin $G M>6 d B$ should be satisfied [4]. From (10), it can be observed that the $d$ - $d$ channel output impedance of the inverter is related to the LCL-filter parameters, the switch frequency, the DC-side voltage and the current-loop regulation parameters. This paper mainly considers the influence of the LCL-filter parameters on the stability margin of the grid-connected system. As the converter-side

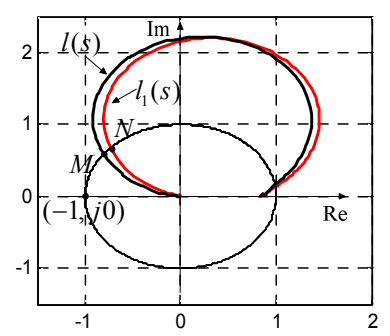

Fig. 10. Nyquist plots for $l_{1}(s)$ and $l(s)$.

inductance $L_{1}$ has little influence on the output impedance $Z_{d d}$, the parameter $L_{1}$ is not discussed in this paper.

According to (23), the magnitude of the eigenvalue $l_{2}(s)$ is always less than $l_{1}(s)$ and the Nyquist plot for the eigenvalue $l_{2}(s)$ is surrounded by $l_{1}(s)$, then the stability margin of the grid-connected system can be studied based on the eigenvalue $l_{1}(s)$ of the return-ratio matrix $\mathbf{L}_{d q}(s)$. In order to analyze the influence of the resistive component in the grid impedance on the stability margin, $l(s)$ is introduced as:

$$
l(s)=\left(s L_{g}+j \omega L_{g}\right) Y_{d d}(s)=Z_{l g}(s) / Z_{d d}(s)
$$

where $\mathrm{Z}_{L g}(s)$ is the inductive component in the grid impedance.

Fig. 10 shows the Nyquist plots for $l_{1}(s)$ and $l(s)$ with the parameters listed in Table I. Point $M$ and point $N$ are the intersections of $l(s)$ and $l_{1}(s)$ with the unit circle. The frequencies at points $M$ and $N$ are the cut-off frequencies of $l(s)$ and $l_{1}(s)$, respectively, and their positions the unit circle determine the phase margin for the system. Obviously, compared with point $M$, point $N$ is far away from $(-1, j 0)$, thus $l_{1}(s)$ has a better stability margin. Therefore, the resistive component in the grid impedance is able to improve the stability margin of the grid-connected system. In order to guarantee a sufficient stability margin for the system, this paper considers extreme cases and $l(s)$ is utilized to analyze the stability margin of system. Therefore, the stability analysis of a grid-connected system with an LCL filter is converted into a study of the $d$ - $d$ channel output impedance $\mathrm{Z}_{d d}(s)$ and the inductive component $\mathrm{Z}_{L g}(s)$ in the grid impedance.

Fig. 11 shows the bode plots with the parameters listed in Table I for the $d$ - $d$ channel output impedance $Z_{d d}(s)$ of the grid-connected inverter and the inductive component $\mathrm{Z}_{L g}(s)$ in the grid impedance. It is observed that point $A$ corresponds 


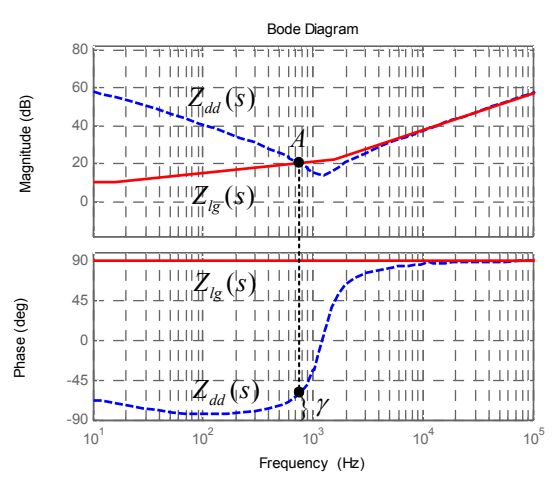

Fig. 11. The bode plots for $\mathrm{Z}_{d d}(s)$ and $\mathrm{Z}_{l g}(s)$.

to the point $M$ in Fig. 10. Then the stability margin of the grid-connected system is determined by the phase of the output impedance $Z_{d d}$ at point $A . \gamma$ in Fig. 11 depicts the phase margin for the system.

Since the stability margin of the system is determined by the phase of the output impedance $Z_{d d}(s)$ at point $A$, this paper regards point $A$ as the stable point of the system. The influences of the damping resistance $R_{d}$, the filter capacitance $C_{f}$ and the grid-side inductance $L_{2}$ on the stable point $A$ are shown in Fig. 12 and the corresponding LCL parameters are shown in Table II. The inductance $L_{g}$ in the grid impedance remains $1 \mathrm{mH}$. In Fig. 12(a), it can be seen that with the increase of $R_{d}$, the resonance peak of the output impedance $Z_{d d}(s)$ decreases gradually, point $A$ moves upward along the amplitude-frequency curve of $\mathrm{Z}_{L g}(s)$ and the phase margin of the system increases. In Fig. 12(b), as the filter capacitor $C_{f}$ increases, the gain of the output impedance $Z_{d d}(s)$ decreases in the low frequency range and it keeps invariant in the high frequency range. The resonance peak moves towards the left, the stable point $A$ moves down along the amplitude-frequency curve of $Z_{L g}(s)$ and the phase margin for the system increases. In Fig. 12(c), as the grid-side inductance $L_{2}$ increases, the gain of the output impedance $Z_{d d}(s)$ keeps invariant in the low frequency range and it increases in the high frequency range. The resonance peak moves towards the left, the stable point $A$ moves down along the amplitude-frequency curve of $\mathrm{Z}_{L g}(s)$, the phase margin for the system increases and the stability of the grid-connected inverter increases as well.
TABLE II

LCL PARAMETERS IN THE SIMULATIONS

\begin{tabular}{ccccc}
\hline & $L_{1}$ & $L_{2}$ & $C_{f}$ & $R_{d}$ \\
\hline \multirow{2}{*}{$R_{d}$} & $1 \mathrm{mH}$ & $1.2 \mathrm{mH}$ & $14.1 \mu \mathrm{F}$ & $2 \Omega$ \\
changed & $1 \mathrm{mH}$ & $1.2 \mathrm{mH}$ & $14.1 \mu \mathrm{F}$ & $5 \Omega$ \\
& $1 \mathrm{mH}$ & $1.2 \mathrm{mH}$ & $14.1 \mu \mathrm{F}$ & $15 \Omega$ \\
\hline \multirow{2}{*}{$C_{f}$} & $1 \mathrm{mH}$ & $1.2 \mathrm{mH}$ & $4.7 \mu \mathrm{F}$ & $5 \Omega$ \\
changed & $1 \mathrm{mH}$ & $1.2 \mathrm{mH}$ & $14.1 \mu \mathrm{F}$ & $5 \Omega$ \\
& $1 \mathrm{mH}$ & $1.2 \mathrm{mH}$ & $23.5 \mu \mathrm{F}$ & $5 \Omega$ \\
\hline \multirow{2}{*}{$L_{2}$} & $1 \mathrm{mH}$ & $1 \mathrm{mH}$ & $4.7 \mu \mathrm{F}$ & $5 \Omega$ \\
changed & $1 \mathrm{mH}$ & $2 \mathrm{mH}$ & $4.7 \mu \mathrm{F}$ & $5 \Omega$ \\
& $1 \mathrm{mH}$ & $3 \mathrm{mH}$ & $4.7 \mu \mathrm{F}$ & $5 \Omega$ \\
\hline
\end{tabular}

As analyzed above, in the case of a high impedance grid, the stability of the grid-connected inverter is improved by regulating the LCL parameters. Thus based on the conventional design technique for an LCL filter, (10) can be regarded as a guideline for the filter design, which should consider the following two aspects: the electric property of the converter itself and the stability of the system. In (10), the $d$ - $d$ channel output impedance of the inverter is unduly complicated and not applied to practical designing, thus it needs to be simplified. Neglecting the high-order term $\left(s C_{f} R_{d}+1\right)^{2} / \Delta\left(1+T_{m}\right)$, the output impedance $Z_{d d}(s)$ is approximated as:

$$
Z_{d d}(s)=-\frac{\hat{e}_{d}}{\hat{i}_{2 d}} \approx s L_{2}+\frac{1}{s C_{f}}+R_{d}
$$

From (25), it is observed that the simplified $d$ - $d$ channel output impedance $\mathrm{Z}_{d d}(s)$ can be regarded as a series connection of the grid-side inductance and the capacitor branch. In Fig. 13, curves I and II are frequency characteristic curves of the original $d-d$ channel output impedance and the simplified $d$ - $d$ channel output impedance. It is evident that at high and intermediate frequencies, curves I and II are almost coincident except that there are differences in the gain and the phase of the output impedance $Z_{d d}(s)$ at low frequencies. The position of the stable point $A$ is almost unchanged. Thus (25) can be used for designing the $d$-d channel output impedance of a grid-connected inverter with an LCL filter. 


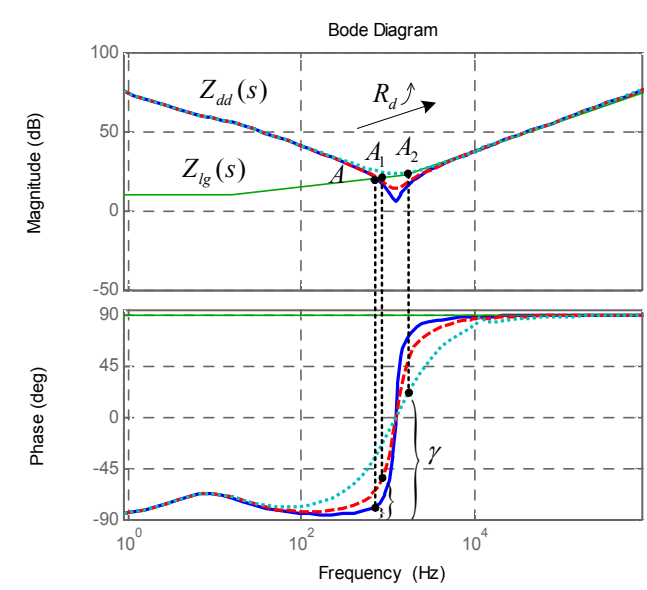

(a) The change regulation of the stable point $A$ when the damping resistance $R_{d}$ is increased.

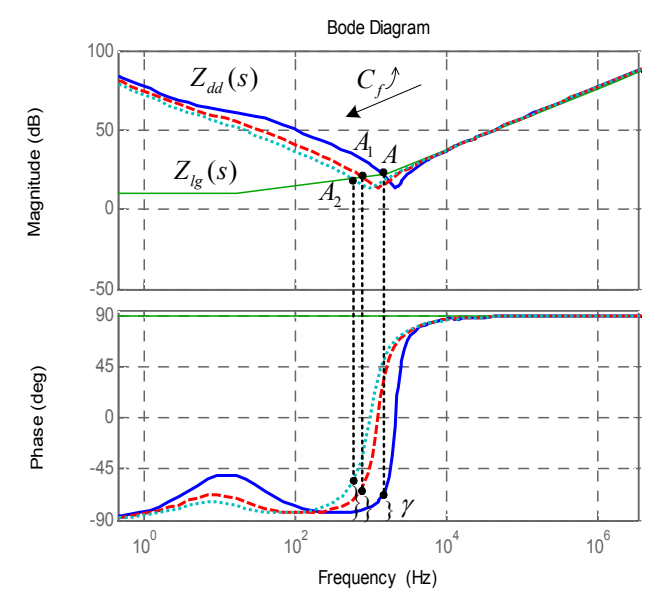

(b) The change regulation of the stable point $A$ when the filter capacitance $C_{f}$ is increased.

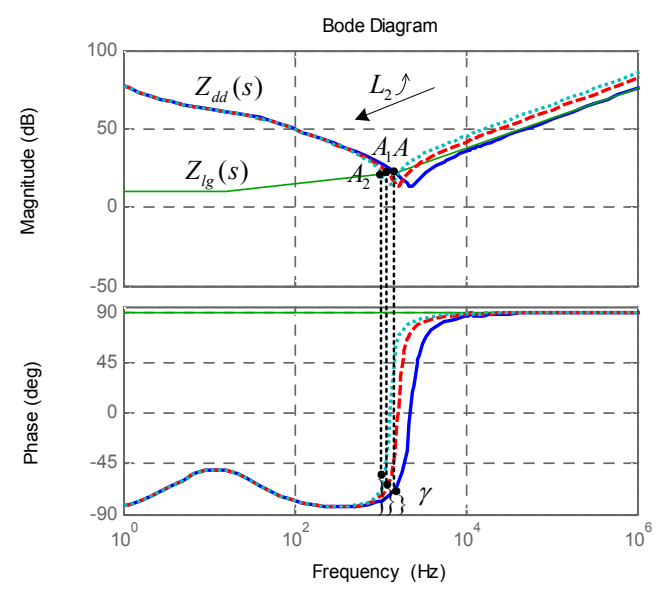

(c) The change regulation of the stable point $A$ when the gridside inductance $L_{2}$ is increased.

Fig. 12. The influence of the LCL parameters on the stable point A.

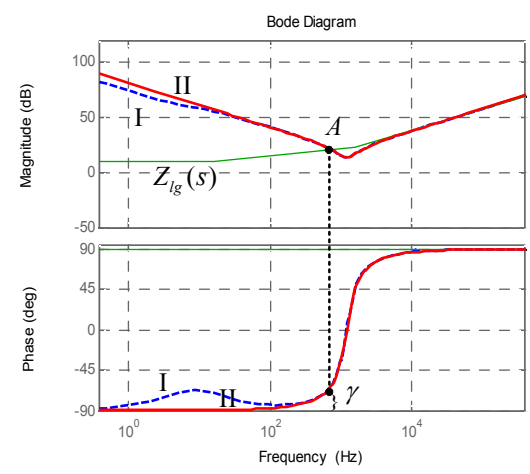

Fig. 13. The comparison of the frequency characteristic curves of $\mathrm{Z}_{d d}(s)$ between the original one and the simplified one.

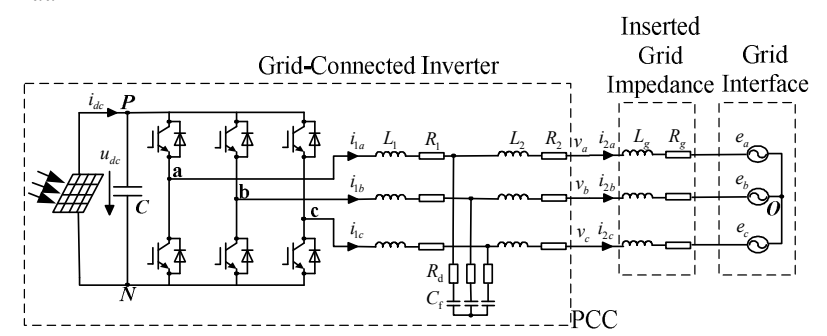

Fig. 14. The power circuit of experiments.

\section{EXPERIMENTAL RESULTS}

In order to verify the influence of the grid impedance on a grid-connected inverter with an LCL filter, experiments are implemented on a $10 \mathrm{~kW}$ three-phase PV inverter platform by using a floating point DSP (Texas Instruments TMS320F28335) as the algorithm controller. A Xilinx FPGA $\mathrm{XC} 3 \mathrm{~S} 400$ is used as the peripheral auxiliary controller for implementing the pulse output, external AD/DA control, fault protection and other functions. The direct current control method is adopted. The outer voltage loop controls the DC bus voltage and the inner current loop controls the $\mathrm{AC}$ current. The grid phase is tracked by a software phase-locked loop (SPLL). The parameters of the experiments are described in Table I. All of the experiments are implemented on the basis of the parameters in Table I.

In order to analyze the influence of the grid impedance, the experiments are implemented by inserting inductors and resistors at the PCC in series with the grid to simulate the grid impedance as shown in Fig. 14.

The output voltage of the PV arrays is controlled by adopting the constant voltage method for tracking the maximum power point in this paper. Fig. 15(a) and Fig. 15(b) show the waveforms and FFT of the grid current by adopting the grid-side current control method and the converter-side current control method, respectively without the inserted inductors and resistors. The THD is $2.3 \%$ when controlled with the grid-side current and $2.4 \%$ when controlled with the converter-side current. It can be seen that the grid-connected inverter can operate in a stable condition and the output 


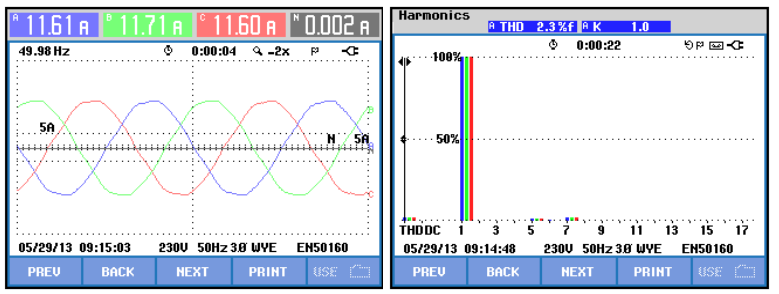

(a)

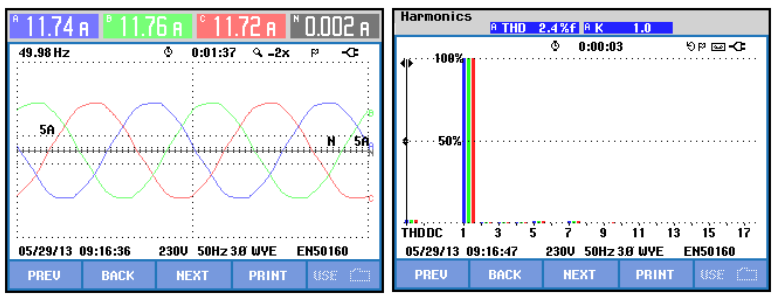

(b)

Fig. 15. Waveforms and FFT of grid current by adopting different current control methods when the grid impedance is zero in value. (a) Grid-side current control method; (b) Converter-side current control method.

currents meet the harmonics requirements with both of the two current control methods.

Fig. 16 shows the output current by adopting the grid-side current control method and the converter-side current control method, when the inductance $L_{g}$ and the resistance $R_{g}$ in the grid impedance are $5 \mathrm{mH}$ and $1 \Omega$. From Fig. 16(a) and Fig. 16(b), it can be observed that the grid-connected system is unstable while adopting the grid-side current control method with the larger damping resistance and filter capacitance. Compared with the grid-side current control method, the grid-connected system has a higher stability when controlled with the converter-side current. Fig. 17 shows the Nyquist plots for the eigenvalue $l_{1}(s)$ of the return-ratio matrix $\mathbf{L}_{d q}(s)$ and Fig. 18 shows the zero-pole plots for the $d$-d channel output admittance $Y_{d d}(s)$. The Nyquist plots and zero-pole plots correspond to the output current in Fig. 16. It is observed that the Nyquist plots for the eigenvalue $l_{1}(s)$ do not encircle the point $(-1, j 0)$ when controlled with the grid-side current and the converter-side current. However, the $d$ - $d$ channel output admittance $Y_{d d}(s)$ controlled with the grid-side current contains positive real poles. It is obvious that this system does not satisfy the generalized Nyquist stability criterion. In Fig. 16(c) and Fig. $16(\mathrm{~d}), C_{f}$ is changed from $14.1 \mu \mathrm{F}$ to $23.5 \mu \mathrm{F}$, and the stability of the grid-connected inverter is developed correspondingly. As $C_{f}$ increases, the phase margin becomes larger to improve the system stability.

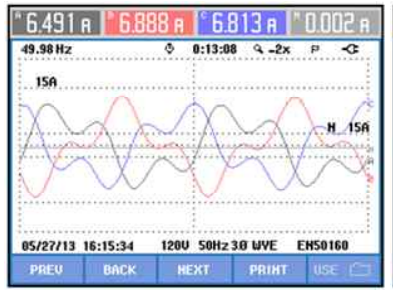

(a)

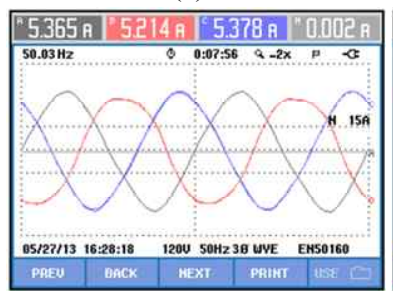

(c)

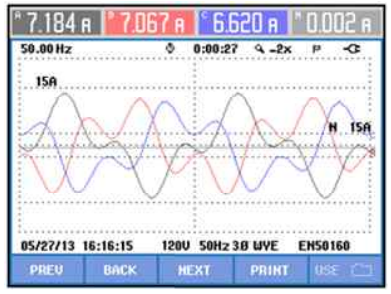

(b)

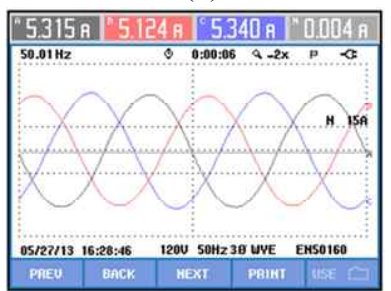

(d)
Fig. 16. Waveforms of grid current by adopting different current control methods when the grid impedance is not zero in value. (a)With the grid-side current control, $C_{f}=14.1 \mu F, R_{d}=14 \Omega$; (b)With the grid-side current control, $C_{f}=23.5 \mu F, R_{d}=14 \Omega$; (c)With the converter-side current control, $C_{f}=14.1 \mu F, R_{d}=14 \Omega ;$ (d)With the converter-side current control, $C_{f}=23.5 \mu F, R_{d}=14 \Omega$.

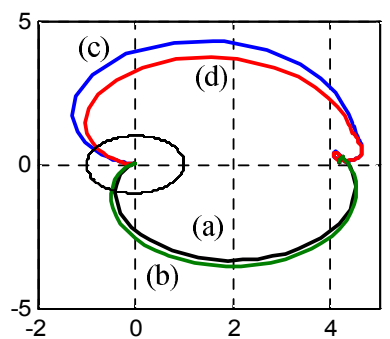

Fig. 17. Nyquist plots for the eigenvalue $l_{1}(s)$ of the return-ratio matrix $\mathbf{L}_{d q}(s)$.
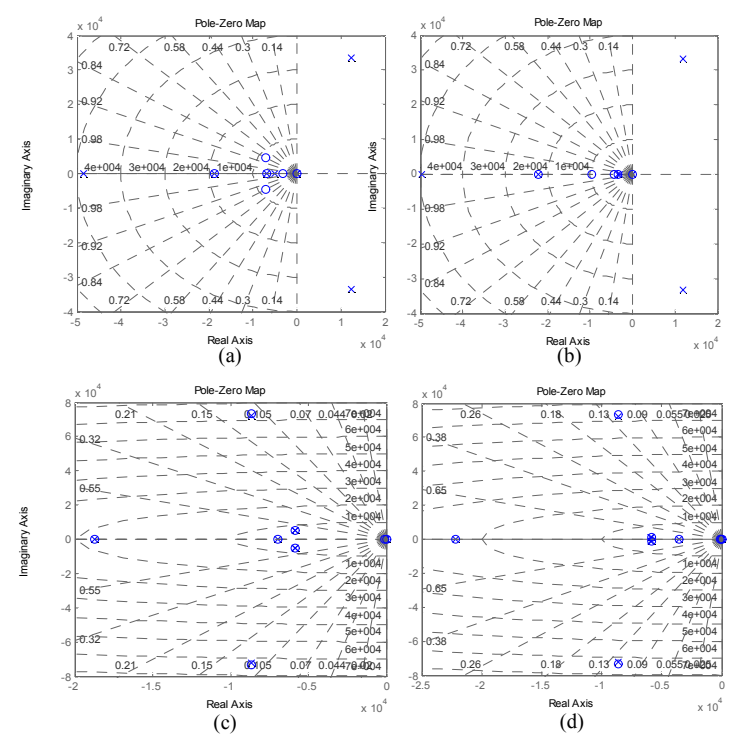

Fig. 18. The zero-pole plots for the $d-d$ channel output admittance $Y_{d d}(s)$. 
TABLE III

LCL FILTER AND GRID IMPEDANCE PARAMETERS IN THE EXPERIMENTS

\begin{tabular}{ccccccc}
\hline & $L_{1}$ & $L_{2}$ & $C_{f}$ & $R_{d}$ & $L_{g}$ & $R_{g}$ \\
\hline I & $1 \mathrm{mH}$ & $1.2 \mathrm{mH}$ & $14.1 \mu \mathrm{F}$ & $5 \Omega$ & $5 \mathrm{mH}$ & $1 \Omega$ \\
II & $1 \mathrm{mH}$ & $1.2 \mathrm{mH}$ & $23.5 \mu \mathrm{F}$ & $5 \Omega$ & $5 \mathrm{mH}$ & $1 \Omega$ \\
III & $1 \mathrm{mH}$ & $1.2 \mathrm{mH}$ & $14.1 \mu \mathrm{F}$ & $9 \Omega$ & $5 \mathrm{mH}$ & $1 \Omega$ \\
IV & $1 \mathrm{mH}$ & $1.2 \mathrm{mH}$ & $23.5 \mu \mathrm{F}$ & $9 \Omega$ & $5 \mathrm{mH}$ & $1 \Omega$ \\
V & $1 \mathrm{mH}$ & $1.2 \mathrm{mH}$ & $4.7 \mu \mathrm{F}$ & $5 \Omega$ & $5 \mathrm{mH}$ & $1 \Omega$ \\
VI & $1 \mathrm{mH}$ & $2.7 \mathrm{mH}$ & $4.7 \mu \mathrm{F}$ & $5 \Omega$ & $5 \mathrm{mH}$ & $1 \Omega$ \\
VII & $1 \mathrm{mH}$ & $1.2 \mathrm{mH}$ & $23.5 \mu \mathrm{F}$ & $5 \Omega$ & $6.5 \mathrm{mH}$ & $1 \Omega$ \\
\hline
\end{tabular}

In order to analyze the influence of different LCL filter parameters on the grid-connected inverter under high grid impedance conditions, relative experiments are implemented. The adopted LCL parameters and the grid impedance values in the experiments are shown in Table III. Fig. 19 shows the output current of the grid-connected inverter. By comparing Figs. 19(a) and 19(b) with Figs. 19(c) and 19(d), it can be observed that as the filter capacitance increases, the output current of the grid-connected inverter tends to be increasingly stable. The theoretical analysis are shown in Figs. 20(a) and 20(b). By comparing Figs. 19(a) and 19(c) with Figs. 19(b) and $19(\mathrm{~d})$, as the damping resistance increases, the stability of the grid-connected inverter is developed as well. Figs. 20(c) and 20(d) show that the phase margin $\gamma$ increases when the damping resistance increased. From Figs. 19(e) and 19(f), as the grid-side inductance of the LCL filter increases, the stability of the grid-connected inverter is improved to a great extent, which corresponds to the theoretical analysis in Fig. 20(e). Thus the system stability can be improved by regulating the damping resistance, the filter capacitance or the grid-side inductance of the LCL filter. Fig. 19(g) shows the output current with parameters VII. Compared with the grid-side current with parameters II, the phase margin of the grid-connected system will be reduced and the stability decreases when the filter parameters are kept invariant and the inductance in the grid impedance increases, which corresponds to the theoretical analysis in Fig. 20(f).

Fig. 21(a) shows the three-phase grid current waveform when the output active power of the grid-connected inverter increases from $900 \mathrm{~W}$ to $1300 \mathrm{~W}$ with parameter I in Table III. It is shown that the stability of the system has no obvious improvement when the output active power changes. It can be seen that the operating point of the system has little influence on system stability. Fig. 21(b) shows the output current with parameters I in Table III when the inductive load is paralleled with the grid at the PCC. The inductance $L_{l}$ and the resistance $R_{l}$ in the inductive load are $3 \mathrm{mH}$ and $15 \Omega$, respectively. As can be seen, when compared with Fig. 19(a),

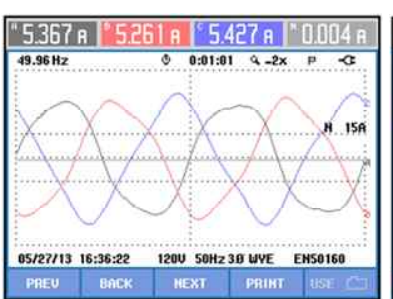

(a)

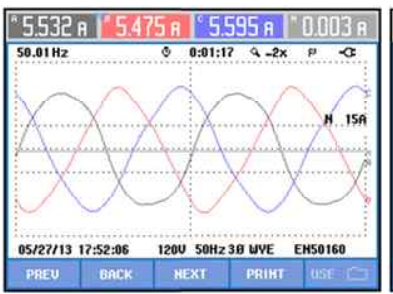

(c)

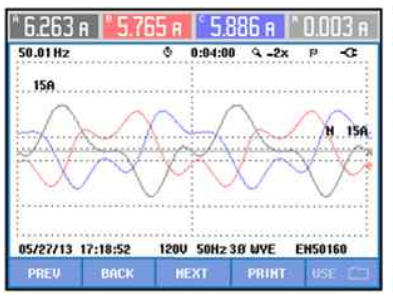

(e)

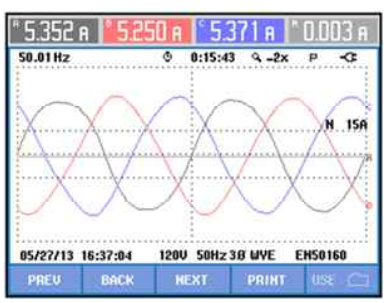

(b)

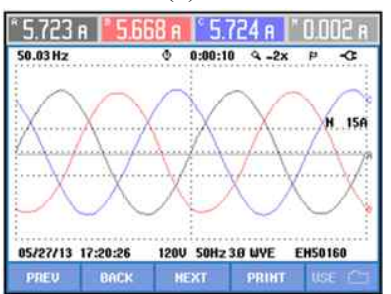

(d)

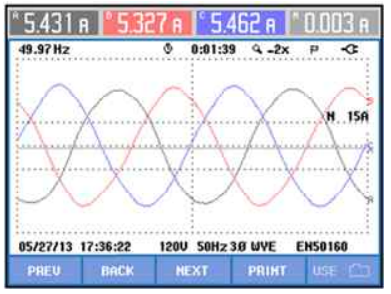

(f)

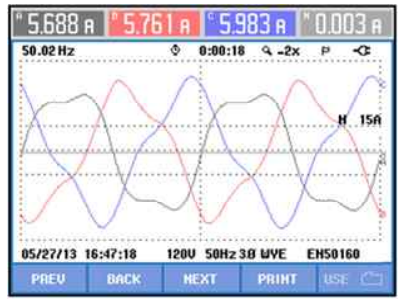

(g)

Fig. 19. Grid-side output current with different filter parameters. (a)With parameter I; (b)With parameter II; (c)With parameter III; (d)With parameter IV; (e)With parameter V; (f)With parameter VI; (g)with parameter VII.

the stability of the system is improved. When the inductive load is paralleled with the grid, the equivalent grid impedance at the PCC is changed, and the inductive component in the equivalent grid impedance decreases. Then the phase margin of the grid-connected system increases.

\section{CONCLUSIONS}

In this paper, the theoretical basis for output impedance calculation is introduced. Based on the small-signal model, the $d$-d channel closed-loop output impedance models controlled with converter-side current and grid-side current are derived, respectively. Specifically, with the simplified stability analysis method, it is shown that the output admittance matrix controlled with the grid-side current has conjugate poles with a positive real part and the gridconnected system does not satisfy the generalized Nyquist 

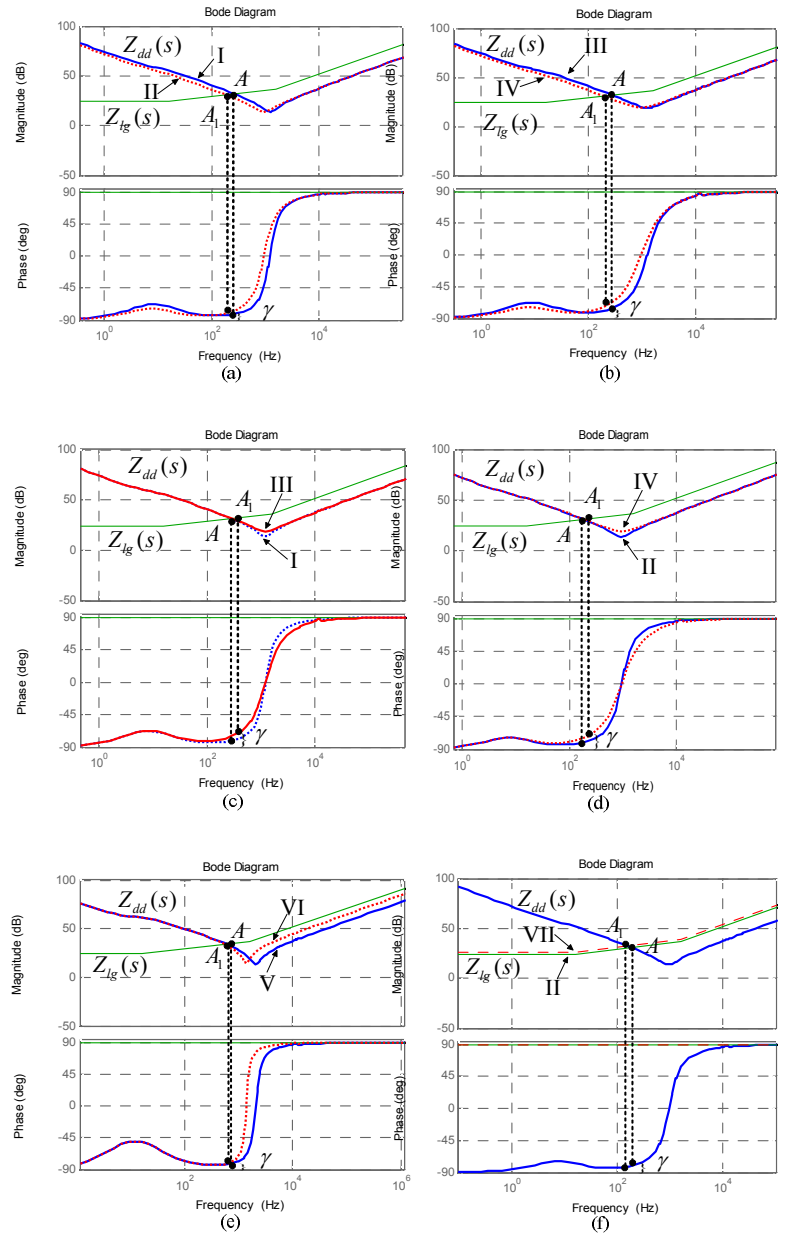

Fig. 20. The influence of the LCL parameters in Table III on the phase margin $\gamma$.

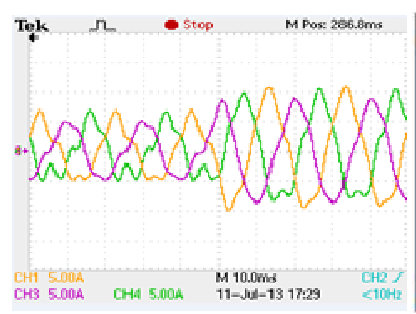

(a)

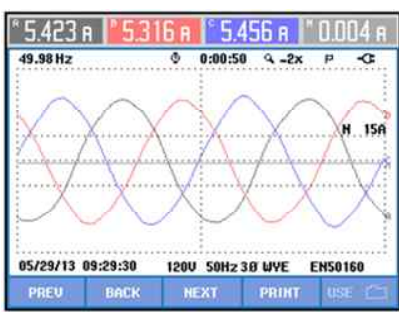

(b)
Fig. 21. The output current of grid-connected inverter. (a) With the active power changed; (b) With the inductive load paralleled.

stability criterion. Further, it is shown that the stability of the grid-connected system controlled with the converter-side current is fully determined by the $d$ - $d$ channel output admittance of the grid-connected inverter and the inductive component of the grid impedance, and the stability margin of the grid-connected inverter can be changed by regulating the LCL parameters. Experimental results validate the proposed theoretical stability analysis.

\section{APPENDIX}

The $d$ channel small signal averaged model of the gridconnected inverter with an LCL filter in an SRF are derived as follows:

$$
\begin{aligned}
& G_{i d 1}(s)=\left.\frac{i_{1 d}}{\hat{d}_{d}}\right|_{\hat{u}_{d c}=0, e_{d}=0}=\frac{U_{d c}}{s L_{1}+\left(1 / s C_{f}+R_{d}\right) / / s L_{2}} \\
& =\frac{U_{d c}\left(s^{2} C_{f} L_{2}+s C_{f} R_{d}+1\right)}{s^{3} C_{f} L_{1} L_{2}+s^{2} C_{f} R_{d}\left(L_{1}+L_{2}\right)+s\left(L_{1}+L_{2}\right)} \\
& G_{i d 2}(s)=\left.\frac{\hat{i_{2 d}}}{\hat{d}_{d}}\right|_{\hat{u}_{d c}=0, \hat{e}_{d}=0}=\left(\begin{array}{l}
\hat{i_{1 d}} \\
\hat{d_{d}} * \frac{\hat{i_{2 d}}}{\hat{i_{1 d}}}
\end{array}\right)_{\hat{u}_{d c}=0, \hat{e}_{d}=0} \\
& =G_{i d 1}(s) * \frac{\hat{i_{2 d}}}{\hat{i}_{1 d}}=G_{i d 1}(s) * \frac{\left(1 / s C_{f}+R_{d}\right)}{\left(1 / s C_{f}+R_{d}\right)+s L_{2}} \\
& =\frac{U_{d c}\left(s C_{f} R_{d}+1\right)}{s^{3} C_{f} L_{1} L_{2}+s^{2} C_{f} R_{d}\left(L_{1}+L_{2}\right)+s\left(L_{1}+L_{2}\right)} \\
& G_{i v}(s)=\left.\frac{\hat{i_{1 d}}}{\hat{e_{d}}}\right|_{\hat{u}_{d c}=0, \hat{d}_{d}=0}=\left(\begin{array}{l}
\hat{i_{2 d}} \\
\frac{\hat{i_{1 d}}}{\hat{e_{d}}} \\
\hat{i_{2 d}}
\end{array}\right)_{\hat{u}_{d c}=0, \hat{d}_{d}=0} \\
& =-\frac{1}{s L_{2}+\left(1 / s C_{f}+R_{d}\right) / / s L_{1}} * \frac{\left(1 / s C_{f}+R_{d}\right)}{\left(1 / s C_{f}+R_{d}\right)+s L_{1}} \\
& =\frac{s C_{f} R_{d}+1}{s^{3} C_{f} L_{1} L_{2}+s^{2} C_{f} R_{d}\left(L_{1}+L_{2}\right)+s\left(L_{1}+L_{2}\right)} \\
& Z_{o o}(s)=-\left.\frac{e_{d}}{\hat{i}_{2 d}}\right|_{\hat{u}_{d c}=0, \hat{d}_{d}=0}=s L_{2}+\left(1 / s C_{f}+R_{d}\right) / / s L_{1} \\
& =\frac{s^{3} C_{f} L_{1} L_{2}+s^{2} C_{f} R_{d}\left(L_{1}+L_{2}\right)+s\left(L_{1}+L_{2}\right)}{s^{2} C_{f} L_{1}+s C_{f} R_{d}+1}
\end{aligned}
$$

Based on the current control diagram in Fig. 6(a), as $\hat{i}_{1 d}^{*}=0$, the following equations can be derived as:

$$
\left\{\begin{array}{l}
\hat{i}_{1 d}=\hat{e}_{d} G_{i v}(s)+\hat{d}_{d} G_{i d 1}(s) \\
\hat{d}_{d}=-\hat{i}_{1 d} F_{i}(s) F_{m}(s) \\
\hat{i}_{2 d}=\left(\left(\hat{i}_{1 d}-\hat{i}_{2 d}\right) Z_{C}(s)-\hat{e}_{d}\right) Z_{L 2}(s)
\end{array}\right.
$$

Combining the first equation with the second equation in (A.5) yields:

$$
\hat{i}_{1 d}=\hat{e}_{d} G_{i v}(s)-\hat{i}_{1 d} T_{m 1}(s)
$$

where $T_{m 1}(s)=F_{i}(s) F_{m}(s) G_{i d 1}(s)$ is the loop gain controlled with the converter-side current. Substitute (32) 
into the third equation in (31), then the $d$ - $d$ channel output impedance controlled with the converter-side current is derived as:

$$
\begin{aligned}
Z_{o c 1}(s)= & -\frac{\hat{e}_{d}}{\hat{i}_{2 d}}=\frac{\left(1+Z_{C}(s) Z_{L 2}(s)\right)\left(1+T_{m 1}(s)\right)}{Z_{L 2}(s)\left(1+T_{m 1}(s)\right)-G_{i v}(s) Z_{C}(s) Z_{L 2}(s)} \\
= & \frac{s^{2} C_{f} L_{2}+s C_{f} R_{d}+1}{\frac{\left(s C_{f} R_{d}+1\right)^{2}}{\Delta(s)\left(1+T_{m 1}(s)\right)}+s C_{f}}
\end{aligned}
$$

where $\Delta(s)=s^{3} C_{f} L_{1} L_{2}+s^{2} C_{f} R_{d}\left(L_{1}+L_{2}\right)+s\left(L_{1}+L_{2}\right)$.

Based on the current control diagram in Fig. 6(b), the following equations can be derived as:

$$
\left\{\begin{array}{l}
\hat{d}_{d}=-\hat{i}_{2 d} F_{i}(s) F_{m}(s) \\
\hat{i}_{2 d}=-\frac{1}{Z_{o o}} \hat{e}_{d}+\hat{d}_{d} G_{i d 2}(s)
\end{array}\right.
$$

The $d-d$ channel output impedance controlled with the grid-side current is derived as:

$$
Z_{o c 2}(s)=-\frac{\hat{e}_{d}}{\hat{i}_{2 d}}=Z_{o o}(s)\left(1+T_{m 2}(s)\right)
$$

where $T_{m 2}(s)=F_{i}(s) F_{m}(s) G_{i d 2}(s)$ is the loop gain controlled with the grid-side current.

\section{ACKNOWLEDGMENT}

The authors would like to thank the National Natural Science Foundation of China (51077124) and the Specialized Research Fund for the Doctoral Program of Higher Education (20120095110017) and the Research and Innovation Program of Postgraduates of Jiangsu Province (CXZZ13_0929) and the Fundamental Research Funds for Central Universities (2013DXS02).

\section{REFERENCES}

[1] H. Langkowski, T. D. Thanh, K. D. Dettmann, and D. Schulz, "Grid impedance determination-relevancy for grid integration of renewable energy systems," in Conference of the IEEE Industrial Electronics Society (IECON'09), pp. 516-521, 2009.

[2] M. Liserre, R. Teodorescu, and F. Blaabjerg, "Stability of photovoltaic and wind turbine grid-connected inverters for a large set of grid impedance values," IEEE Trans. Power Electron., Vol. 21, No. 1, pp. 263-272, Jan. 2006.

[3] M. Liserre, R. Teodorescu, and F. Blaabjerg, "Stability of grid-connected PV inverters with large grid impedance variation," in Proc. IEEE 35th Annu. Power Electron. Spec. Conf., vol. 6, pp. 4773-4779, Jun. 2004.

[4] X. Feng, Z. Ye, K. Xing, F. C. Lee, and D. Borojevic, "Individual load impedance specification for a stable DC distributed power system," in Proc. IEEE APEC'99, pp. 923-929, 1999.
[5] C. Zhu and Y. Yan, "Improved impedance criterion," Journal of Nanjing University of Aeronautics \& Astronautics, Vol. 38, No. 3, pp. 315-320, Jun. 2006.

[6] Q. Tong, D. Zhang, and D. Xu, "Output impedance and stability analysis of converters in distributed power systems," Proceedings of the CSEE, Vol. 31, No. 12, pp. 57-64, Apr. 2011.

[7] S. D. Sudhoff, S. F. Glover, P. T. Lamm, D. H. Schmucker, and D. E. Delisle, "Admittance space stability analysis of power electronic systems," IEEE Trans. Aerosp. Electron. Syst., Vol. 36, No. 3, pp. 965-973, Jul. 2000.

[8] J. Liu, X. Feng, F. C. Lee, and D. Borojevich, "Stability margin monitoring for distributed power systems via perturbation approaches," IEEE Trans. Power Electron., Vol. 18, No. 6, pp. 1254-1261, Nov. 2003.

[9] J. Sun, "Impedance-based stability criterion for gridconnected inverters," IEEE Trans. Power Electron., Vol. 26, No. 11, pp. 3075-3078, Nov. 2011.

[10] S. Hiti, V. Vlatokovic, D. Boroyevich, and F. Lee, "A new control algorithm for three-phase PWM buck rectifier with input displacement factor compensation," IEEE Trans. Power Electron., Vol. 2, No. 2, pp. 173-180, Mar. 1994.

[11] M. Belkhayat. "Stability criteria for ac power systems with regulated loads," PhD. thesis, Purdue University, Dec. 1997.

[12] A. MacFarlane and I. Postlethwaite, "The generalized Nyquist stability criterion and multivariable loci," in Int. Jour of Control, Vol. 25, pp. 81-127, Jan. 1977.

[13] R. Burgos, D. Boroyevich, F. Wang, K.Karimi, and G. Francis, "On the ac stability of high power factor threephase rectifiers," in Proc. IEEE Energy Convers. Congr. Expo., pp. 2047-2054, Sep. 2010.

[14] S. Abe, M. Hirokawa, and T. Ninomiya, "Output impedance design consideration of three control schemes for bus converter in on-board distributed power system," in Proc. 2007 Power Electronics and Drive Systems, 2007. PEDS '07. 7th International Conference, pp. 1199-1204, 2007.

[15] F. Li, X. Zou, Y. Zou, J. Shi, Z. Wu, C. Wang, and J. Tang, "Input impedance analysis of LCL-filter PWM rectifier connected to grid", Transactions of China Electrotechnical Society, Vol. 25, No. 1, pp. 97-103, Jan. 2010.

[16] T. Wu and X. Ruan, "Input impedance analysis of load converters in the distributed power system," Proceedings of the CSEE, Vol. 28, No. 12, pp 20-25, Apr. 2008.

[17] T. Wu and X. Ruan, "Output impedance analysis of source converters in the dc distributed power system," Proceedings of the CSEE, Vol. 28, No. 3, pp 66-72, Jan. 2008.

[18] J. Wang, F. Zhang, C. Gong, and X. Chen, "Study of output impedance optimization for voltage mode control buck dc-dc converter," Transactions of China Electrotechnical Society, Vol. 22, No. 8, pp. 18-23, Aug. 2007.

[19] R. Ahmadi, D. Paschedag, and M. Ferdowsi, "Closed-loop input and output impedances of dc-dc switching converters operating in voltage and current mode control," in Proc. 36th Ann. Conf. IEEE Ind. Electron. Soc., pp. 2311-2316, Nov. 2010

[20] M. Zhao, X. Yang, T. Liu, and J. Liu, "Modeling and stability analysis of a cascaded system composed of photovoltaic simulator and photovoltaic inverter," in Proc. 2012 Applied Power Electronics Conference and 
Exposition (APEC), 2012 Twenty-Seventh Annual IEEE, pp. 2167-2171, 2012.

[21] Y. A. Familiant, J. Huang, K. Corzine, and M. Belkhayat, "New techniques for measuring impedance characteristics of three-phase ac power systems," IEEE Trans. Power Electron., Vol. 24, No. 7, pp. 1802-1810, Jul. 2009.

[22] J. Huang, K. A. Corzine, and M. Belkhayat, "Small-signal impedance measurement of power-electronics-based ac power systems using line-to-line current injection," IEEE Trans. Power Electron., Vol. 24, No. 2, pp. 445-455, Feb. 2009.

[23] D. Xu, F. Wang, Y. Ruan, and H. Mao, “Output impedance modeling of grid-connected inverters considering nonlinear effects," in Proc. 2012 Control and Modeling for Power Electronics (COMPEL), 2012 IEEE 13th Workshop on, pp. 1-7, 2012.

[24] E. Figueres, G. Garcera, J. Sandia, F. Gonzalez-Espein, and J. C. Rubio, "Sensitivity study of the dynamics of threephase photovoltaic inverters with an LCL grid filter," IEEE Trans. Ind. Electron., Vol. 56, No. 3, pp. 706-717, Mar. 2009.

[25] J. Puukko, T. Messo, L. Nousiainen, J. Huusari, and T. Suntio, "Negative output impedance in three-phase gridconnected renewable energy source inverters based on reduced-order model," IET Renewable Power Generation Conf., in press, 2011.

[26] H. Mao, D. Boroyevich, and F. Lee, "Novel reduced-order small-signal model of a three-phase PWM rectifier and its application in control design and system analysis," IEEE Trans. Power Electron., Vol. 13, No. 3, pp. 511-521, May. 1998.

[27] V. Blasko and V. Kaura, "A new mathematical model and control of a three-phase ac-dc voltage source converter," IEEE Trans. Power Electron., Vol. 12, No. 1, pp. 511-521, Jan. 1997.

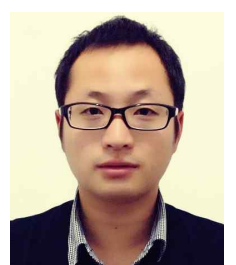

Xiao-Qiang Li was born in Hubei Province, China, in 1987. He received his B.S. and M.S. in Electrical Engineering from the China University of Mining and Technology, Xuzhou, China, in 2010 and 2012, respectively. He is currently working toward his Ph.D. in Electrical Engineering in the Department of Information and Electrical Engineering, China University of Mining and Technology. His current research interests include grid-connected inverter modeling, simulation and control, multilevel inverters and microgrids.

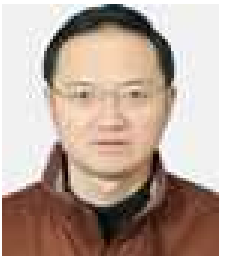

Xiao-Jie Wu was born in Hengyang, Hunan Province, China, in 1966. He received his B.S. in Industrial Automation from the China University of Mining and Technology, Xuzhou, China, in 1988, and his M.S. and $\mathrm{Ph.D.}$ in Electrical Engineering from the China University of Mining and Technology, in 1991 and 2000, respectively. From 2002 to 2004 , he was engaged in postdoctoral research at Tsinghua University, Beijing, China. Since 1991, he has been with the Department of Information and Electrical Engineering, China University of Mining and Technology, where he is currently a Professor. His current research interests include the stability of ac machines, advanced control of electrical machines, and power electronics.

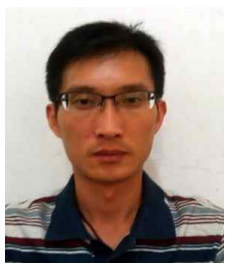

Yi-Wen Geng was born in Jiangsu Province, China, in 1977. He received his B.S. and M.S. in Electrical Engineering from the China University of Mining and Technology, Xuzhou, China, in 2000 and 2004, respectively. He is currently working toward his Ph.D. in Electrical Engineering in the Department of Information and Electrical Engineering, China University of Mining and Technology. Since 2006, he has been with the Department of Information and Electrical Engineering, China University of Mining and Technology, where he is currently a Lecturer. His current research interests include PV inverters, harmonic control and power electronics.

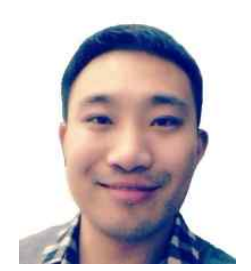

Qi Zhang was born in Jiangsu Province, China, in 1990. He received his B.S. in Electrical Engineering from the China University of Mining and Technology, Xuzhou, China, in 2012. He is currently working toward his M.S. in Electrical Engineering in the Department of Information and Electrical Engineering, China University of Mining and Technology. His current research interests include power electronics modeling, simulation and control, distributed power systems, renewable energy systems and microgrids. 